\title{
Compression behavior and energy absorption capacity of woven flax-epoxy composite under various stain rates
}

\author{
Jianxing $\mathrm{Hu}^{1,2}$, Sha $\mathrm{Yin}^{1,2,3}$, and Jun $\mathrm{Xu}^{1,2,3,4^{*}}$ \\ ${ }^{1}$ Department of Automotive Engineering, School of Transportation Science and Engineering, Beihang University, Beijing 100191, \\ China \\ ${ }^{2}$ Advanced Vehicle Research Center (AVRC), Beihang University, Beijing 100191, China \\ ${ }^{3}$ State Key Laboratory for Strength and Vibration of Mechanical Structures, School of Aerospace Engineering, Xi'an Jiaotong \\ University, Xi'an, 710049, China \\ ${ }^{4}$ State Key Laboratory of Automotive Safety and Energy, Department of Automotive Engineering, Tsinghua University, Beijing, \\ 100084, China
}

\begin{abstract}
Natural fiber reinforced composites serving as building block for structural parts are highly desired due to weight reduction in automotive industry. In the current study, the compressive behavior and energy absorption capacity of woven flax-epoxy composite were experimentally investigated under various strain rates. These tested cubic specimens were manufactured by the vacuum assisted resin infusion (VARI) process and tailoring operation. Quasi-static and dynamic experiments were conducted in a hydraulic servo test machine and a Split Hopkinson Pressure Bar (SHPB), respectively. Preliminary dynamic experimental results revealed significant strain rate sensitivity of woven flax-epoxy composite. The ultimate stress increased by $61.2 \%$ from $185.2 \mathrm{MPa}$ to $298.6 \mathrm{MPa}$ and $25.9 \%$ for specific energy absorption when the strain rate increased from $0.003 / \mathrm{s}$ to $2800 / \mathrm{s}$. Results may serve as a guidance for the further investigation of flax fibers reinforced composites in automotive industry.
\end{abstract}

\section{Introduction}

Due to demands of environmental and energy sustainability, natural fibers reinforced composites have attracted more and more attentions in automotive industry. Natural fibers are regarded as the potential substitutes of synthetic fibers because of the advantages of abundant resources, good recyclability and low cost [1-3].

Flax fiber, as one of natural fibers, and its reinforcement composites are becoming a heated focus with its competitive mechanical behavior over the past decades [4-8]. Some researchers have found that flax fiber possesses comparable specific strength and even better specific modulus compared to glass fiber [1,9], and lower energy consumption in reinforced composite productions [10]. The effect of manufacturing processes on the mechanical behaviors of flax reinforced composites was also investigated, results indicate that processing condition highly affected shear behavior of composite, which is a matrix and interface dominant performance [11]. Most recently, mechanical properties of flax fiber reinforced composites have been reported, including compressive and tensile response as well as fatigue and damage. Bos et al. studied the compressive characteristic of flax-epoxy composites, results show that the kinking of fibers has negative effect on its strength [12]. Charlet et al. found that the tensile properties of flax-epoxy composite would be strengthened when the fiber volume fraction increases [4]. Other studies found that flax fiber architecture has a strong effect on the fatigue behavior [13] and decaying stiffness and permanent deformation could be used to evaluate damage evolution of flax-composites [14]. The typical mechanical parameters of flax fiber composite material, such as modulus, strength and failure strain, were measured experimentally [11, 15-17]. In addition, a multi-scale method and a statistical study were proposed recently by Blanchard et al [18] and Torres et al [19], respectively. Actually, flax fiber reinforced composite extremely likely to experience dynamic loading environment during the services as a structural/semistructural part or an energy absorber [20-24].

However, the aforementioned studies are lack of discussions on strain rate effect of composite material reinforced with flax fiber, which greatly hinders its application in the industry. To bridge this gap, in current study, the quasi-static and dynamic experiments were conducted to explore the strain rate effect of the woven flax-epoxy laminate composite. The compressive behavior and energy absorption capacity were discussed.

\section{Method}

\subsection{Specimen manufacture}

The woven flax/epoxy laminate composite used in our

Corresponding author: junxu@buaa.edu.cn. 
study was fabricated based on the vacuum assisted resin infusion (VARI) process, presented in Fig. 1 (a). Firstly, flax weaves, release cloth and resin infusion net were stacked on the aluminum sheet mould after painting the mould releasing agent. To vacuum and inject the resin (LY 1564/Aradur 22962, Huntsman), two spiral pipes were put aside the stacked flax weaves, respectively. Secondly, the entire laminate was sealed with adhesive sealant and a vacuum bag, then beginning to infuse the epoxy resin until fully saturating the flax weaves. Finally, the whole assembly was transferred into an oven at $80{ }^{\circ} \mathrm{C}$ for up to 2 hours and following $120{ }^{\circ} \mathrm{C}$ for up to 3 hours to cure. After the VARI process, a rectangular composite laminate was obtained shown in Fig. 1 (b), then it was manufactured into the cubic specimens 10 $\mathrm{mm} \times 10 \mathrm{~mm} \times 10 \mathrm{~mm}$ shown in Fig. 1 (c) for mechanical tests. The faces of these specimens were polished to ensure the flatness and parallelism of the two loading surfaces.

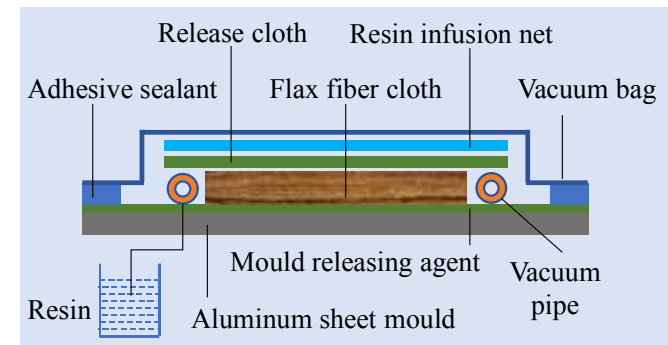

(a)

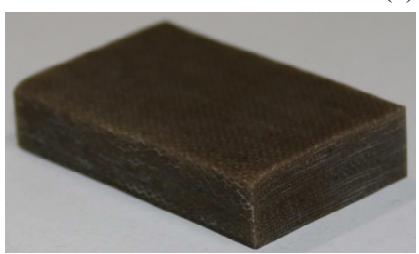

(b)

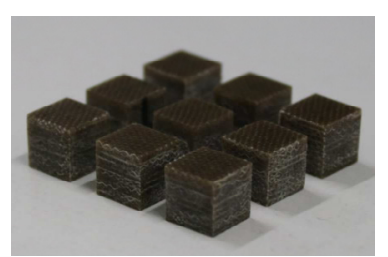

(c)
Fig. 1. Specimen manufacture: (a) schematic of vacuum assistant resin infusion (VARI) process; (c) composite laminate; (d) cubic specimens.

\subsection{Experimental procedures from quasi-static to dynamic loading}

Quasi-static compressive tests were conducted in an INSTRON-8801 shown in Fig. 2 (a). A constant loading speed of $2 \mathrm{~mm} / \mathrm{min}$ corresponding to the strain rate of $0.003 / \mathrm{s}$ and room temperature was adopted.

On the other hand, a conventional Split Hopkins Pressure Bar (SHPB) testing system was used to carry out the dynamic compressive tests shown in Fig. 2 (b) and (c). The material parameters of these bars are density $\rho=8400 \mathrm{~kg} / \mathrm{m}^{3}$, elastic modulus $E=210 \mathrm{GPa}$. The length of strike, incident and transmitted bars are 300 $\mathrm{mm}, 1200 \mathrm{~mm}$ and $1200 \mathrm{~mm}$, respectively. All these bars share the same diameter of $19 \mathrm{~mm}$.
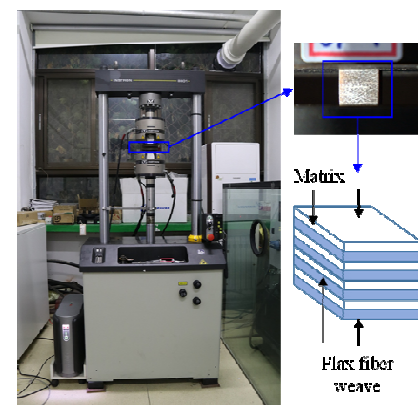

(a)

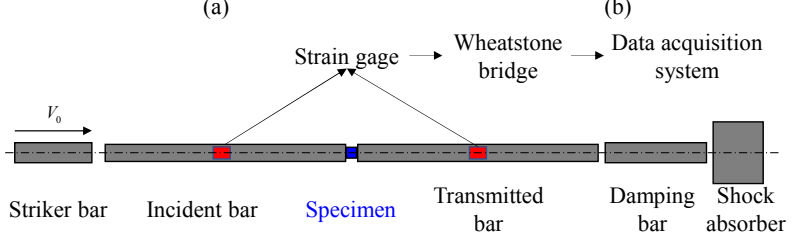

(c)

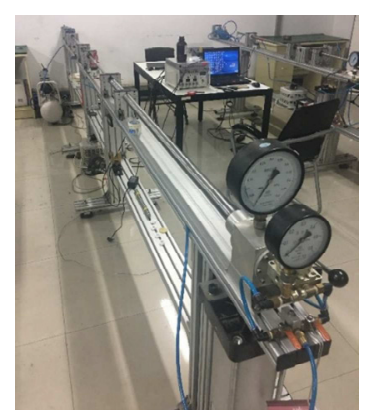

(b)

Damping Shock
Fig. 2. Experimental devices and method: (a) INSTRON-8801 for quasi-static loading; (b) SHPB testing system for dynamic loading; (c) testing principle schematic of SHPB.

For the dynamic loading test, a cubic specimen was sandwich between the incident bar and transmitted bar. Then a gas gun launched the strike bar to impact the incident bar, an elastic compressive wave was produce in the incident bar then propagated towards the specimen. Once the compressive stress wave reached the interface between the incident bar and specimen, part of the stress wave was reflected back into the incident bar, while the remaining propagated through the specimen into the transmitted bar.

Since all bars have a large slenderness ratio, wave propagating in these bars could be assumed as onedimensional elastic wave problem. Therefore, the engineering strain, engineering stress and strain rate could be calculated as the following Eqs. (1)-(3) under the hypothesis of stress equilibrium within the specimen

$$
\begin{gathered}
\varepsilon(t)=-\frac{2 c_{0}}{L_{\mathrm{s}}} \int_{0}^{t} \varepsilon_{\mathrm{r}}(t) \mathrm{d} t \\
\sigma(t)=\frac{A_{\mathrm{b}} E_{\mathrm{b}}}{A_{\mathrm{s}}} \varepsilon_{\mathrm{t}}(t) \\
\dot{\varepsilon}(t)=\frac{2 c_{0}}{L_{\mathrm{s}}} \varepsilon_{\mathrm{r}}(t)
\end{gathered}
$$

where $L_{\mathrm{s}}, A_{\mathrm{s}}$ and $A_{\mathrm{b}}$ are length ,cross sectional area of specimen and bar, respectively. $c_{0}$ and $E_{\mathrm{b}}$ refer to wave speed and Young's modulus of the bars. $\varepsilon_{\mathrm{i}}(t), \varepsilon_{\mathrm{r}}(t)$ and $\varepsilon_{\mathrm{t}}(t)$ are incident, reflected and transmitted wave pulse, respectively, recorded on the incident and transmitted bars as functions of time.

\section{Results and discussion}

\subsection{Compression characteristics}

Fig. 3 shows the engineering stress-strain curves and the final failure modes of woven flax-epoxy laminate composite under quasi-static compression. Two repeated 
tests were conducted and good consistency was observed. From the curves, one can find that the constitutive behavior of the tested material shows a bi-linear feature, i.e. the curve firstly experiences a linear increase within initial elastic response, then the slope gradually decreases up to an approximate yield point and entered the plastic reinforcement phase, highly similar to some typical materials such as dual phase steel [25], silkworm cocoon [26] and 3D braided composite [27]. The final failure modes are confirmed to be shear failure where a visible diagonal cracks through the flax weave layers in each specimen can be observed shown in Fig. 3.

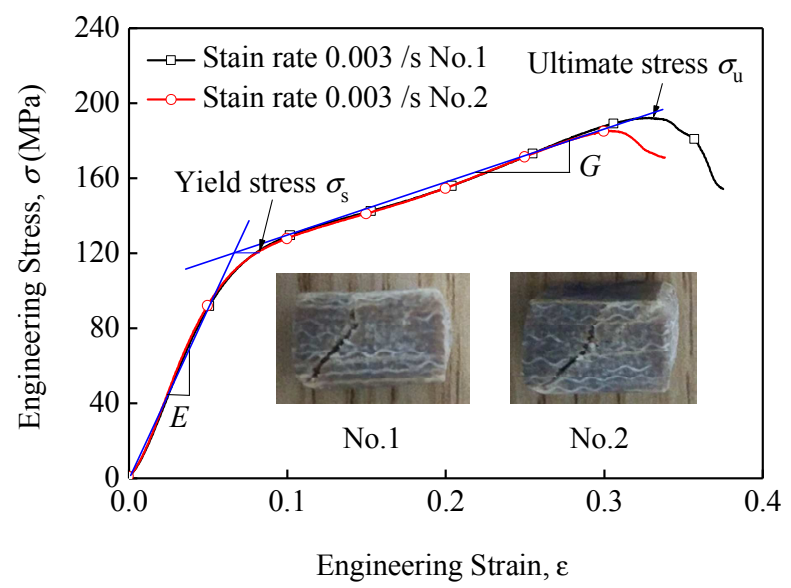

Fig. 3. Engineering stress-strain curves and failure modes under quasi-static loading.

Similar to the quasi-static tests, two repeated experiments were also conducted to ensure the good reproducibility of dynamic experiments. To record the incident, reflected and transmitted wave pulses, two strain-gages were cemented on the incident and transmitted bars, respectively. The typical waveforms in terms of voltages are shown in Fig. 4.

Fig. 4 (a) and (b) are correspond to impact pressure of 0.05 and $0.3 \mathrm{MPa}$, respectively. The amplitude of the incident waveform is a function of impact pressure apparently and the reflected waveform depicts the strain rate, which increases rapidly to the ultimate value, then fluctuates and drops to zero finally. For convenience, the stain rate is defined based on the initial slope of straintime curve, then approximate $500 / \mathrm{s}$ and $1800 / \mathrm{s}$ were obtained for Fig. 4 (a) and (b), respectively. For the two strain rates, the transmitted waveforms have an obvious difference, the former has a linearly elastic increase then a quick drop, while the latter has a plastic reinforcement process after linearly elastic increase. This can be explained as the fact that the specimen is not fully loaded at $\dot{\varepsilon}=500 / \mathrm{s}$ such that the sample deforms elastically.

Furthermore, the above waveforms could be translated into strain $\varepsilon_{\mathrm{i}}(t), \varepsilon_{\mathrm{r}}(t)$ and $\varepsilon_{\mathrm{t}}(t)$ such that the dynamic engineering strain and engineering stress could be calculated based on Eqs. (1)-(2).

Fig. 5 shows the dynamic engineering stress-strain curves and the final failure modes among various strain rates. Results indicate that compressive behavior of woven flax-epoxy laminate composites is strain rate sensitive. A bi-linear feature on the dynamic engineering stress-strain curves could be observed similar to its quasi-static behavior. Meanwhile, the fluctuations appear at $\dot{\varepsilon}=1800 / \mathrm{s}$ and $\dot{\varepsilon}=2800 / \mathrm{s}$, and this may be explained by the intermittent delamination damage of specimens. Particularly, the specimen break apart into several parts because of the flax weave rupture at the higher strain rate $\dot{\varepsilon}=2800 / \mathrm{s}$.
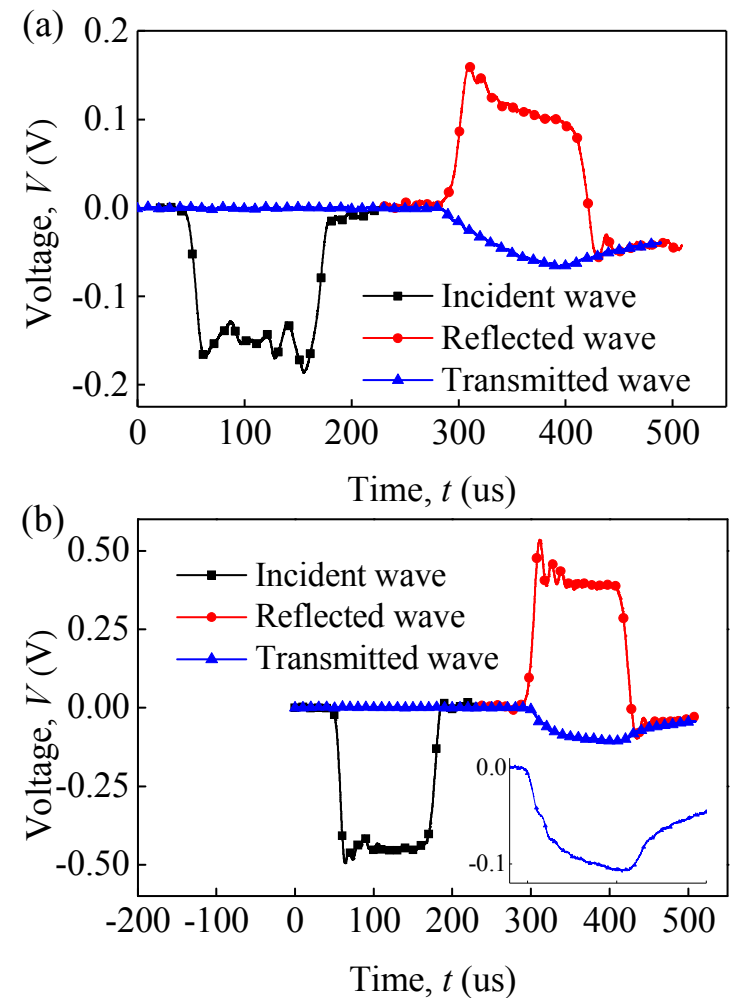

Fig. 4. Typical wave features under different strain rates: (a) $500 / \mathrm{s}$; (b) $1800 / \mathrm{s}$.

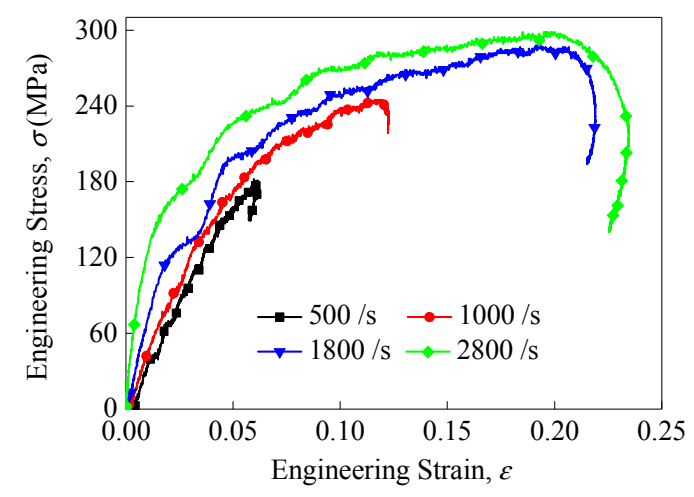

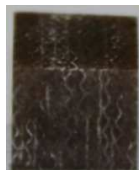

$500 / \mathrm{s}$

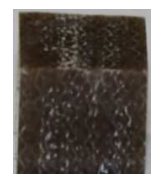

$1000 / \mathrm{s}$

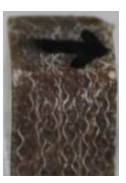

$1800 / \mathrm{s}$

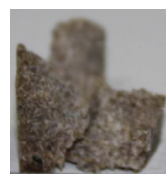

$2800 / \mathrm{s}$
Fig. 5. Dynamic engineering stress-strain curves and the final deformation modes.

To quantitatively discuss strain rate effect of woven flax-epoxy composites, elastic modulus $E_{\mathrm{s}}$, tangent modulus $G_{\mathrm{s}}$, ultimate stress $\sigma_{\mathrm{u}}$ and yield stress $\sigma_{\mathrm{y}}$ extracted from Fig. 3 and Fig. 5 are listed in Table 1. 
These results show that $E_{\mathrm{s}}$ increases from 1.76 to 11.63 $\mathrm{GPa}$, while $\sigma_{\mathrm{u}}$ experiences an increase of $61.2 \%$ to 298.6 $\mathrm{MPa}$ from 185.2 $\mathrm{MPa}$ when the strain rate varies from $0.003 / \mathrm{s}$ to $2800 / \mathrm{s}$. However, $\sigma_{\mathrm{u}}$ is smaller at $\dot{\varepsilon}=500 / s$ than that at $\dot{\varepsilon}=0.003 / s \quad$ (quasi-static loading) and it is due to the inadequate loading at $\dot{\varepsilon}=500 / \mathrm{s}$. Therefore, the tangent modulus is not obtained because of an indistinct plastic reinforcement phase.

Table 1. Mechanical properties of specimens at various strain rates.

\begin{tabular}{ccccc}
\hline$\dot{\varepsilon}(/ \mathrm{s})$ & $\begin{array}{c}E_{\mathrm{s}} \\
(\mathrm{GPa})\end{array}$ & $\begin{array}{c}G_{\mathrm{s}} \\
(\mathrm{GPa})\end{array}$ & $\begin{array}{c}\sigma_{\mathrm{u}} \\
(\mathrm{MPa})\end{array}$ & $\sigma_{\mathrm{y}}(\mathrm{MPa})$ \\
\cline { 1 - 1 } 0.003 & 1.76 & 0.29 & 185.2 & 120.06 \\
500 & 3.28 & $/$ & $/$ & $/$ \\
1000 & 4.01 & 0.41 & 244.9 & 234.41 \\
1800 & 6.59 & 0.40 & 290.7 & 250.12 \\
2800 & 11.63 & 0.41 & 298.6 & 268.46 \\
\hline
\end{tabular}

\subsection{Energy absorption with different strain rates}

Integrating the quasi-static and dynamic engineering stress-strain curves in Fig. 3 and Fig. 5, the energy absorption curves of various strain rates are obtained as shown in Fig. 6. It is noted that the energy absorption of woven flax-epoxy composites increases with strain rate at an equal strain level. The mechanism for this phenomenon may be that the formation and propagation of cracks in matrix as well as flax fibers fracture may consume more energy at a higher strain rate. Particularly, the specimen fracture into several debris at $\dot{\varepsilon}=2800 / \mathrm{s}$ as shown in Fig. 5. Another reason could be that both flax fiber and epoxy resin matrix are strain rate sensitive materials [28-30]. These factors together contribute to achieving the phenomenon that higher strain rate could enhance the energy absorption capacity of woven flaxepoxy composite.

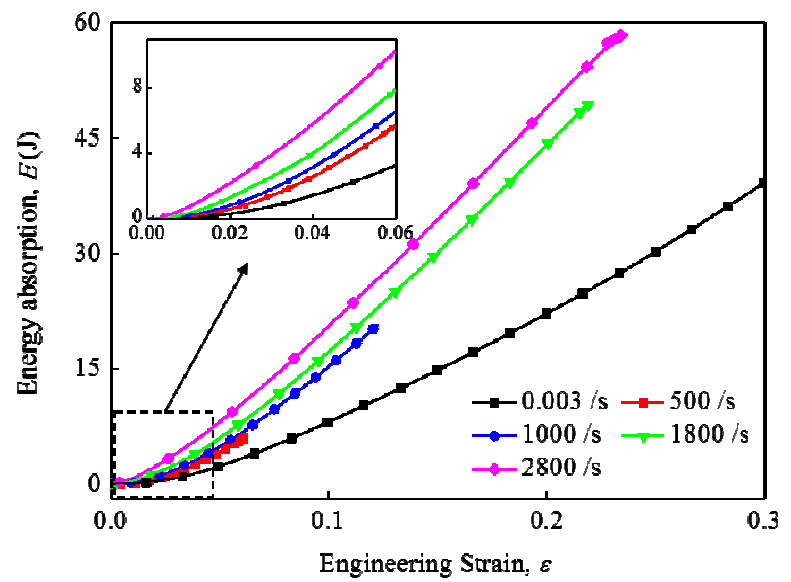

Fig. 6. Energy absorption capacity with engineering strain under various strain rates.

\section{Conclusions}

Flax fiber reinforced composites may be regarded as the potential substitutes of synthetic fibers in automotive engineering applications. Thus, in current study, the strain rate effect on the compressive behavior and energy absorption capacity of woven flax-epoxy composites were experimentally investigated. The engineering stress-strain curves and energy absorption curves at five various strain rates were collected together to compared, respectively. Remarkable strain rate effect is observed for both compressive properties and energy absorption capacity. Elastic modulus, yield stress and ultimate stress all increase with the strain rate, and even ultimate stress experiences an increase of $61.2 \%$ from $185.2 \mathrm{MPa}$ to 298.6 $\mathrm{MPa}$ when the strain rate varies from $0.003 / \mathrm{s}$ to 2800 /s. Meanwhile, the mechanism of strain rate sensitivity for the energy absorption capacity was analyzed. Formation and propagation of cracks in matrix as well as strain rate sensitivity constituents induce that more energy can be absorbed as strain rate increases.

Results may provide the guidance for the further investigation of mechanical behaviors of flax fibers reinforced composites and their wide application in automotive and aeronautics related industry.

This work is financially supported by start-up funds of "The Recruitment Program of Global Experts" awardee from Beihang University (ZG216S1769), Research Project of the State Key Laboratory of Vehicle NVH and Safety Technology (NVHSKL-201610), Opening fund of State Key Laboratory of Automotive Safety and Energy, Tsinghua University (KF16142) and Opening fund of State Key Laboratory for Strength and Vibration of Mechanical Structures, Xi'an Jiaotong University (SV2015-KF-07, SV2016-KF-20).

\section{References}

1. D.B. Dittenber, H.V.S. GangaRao, Compos Part AAppl S 43(8) 1419-1429 (2012)

2. G. Koronis, A. Silva, M. Fontul, Compos Part B-Eng 44(1) 120-127 (2013)

3. F.M. Al-Oqla, S.M. Sapuan, J. Clean Prod. 66 347354 (2014)

4. K. Charlet, C. Baley, C. Morvan, J.P. Jernot, M. Gomina, J. Breard, Compos Part A-Appl S 38(8) 1912-1921 (2007)

5. K. Charlet, J.-P. Jernot, M. Gomina, L. Bizet, J. Breard, J Compos Mater 44(24) 2887-2896 (2010)

6. A.S. Doumbia, M. Castro, D. Jouannet, A. Kervoelen, T. Falher, L. Cauret, A. Bourmaud, Mater. Des. 87 331-341 (2015)

7. M. Kersani, S.V. Lomov, A.W. Van Vuure, A. Bouabdallah, I. Verpoest, J Compos Mater 49(4) 403413 (2015)

8. L. Yan, N. Chouw, K. Jayaraman, Compos Part BEng 56 296-317 (2014)

9. S.V. Joshi, L.T. Drzal, A.K. Mohanty, S. Arora, Compos Part A-Appl S 35(3) 371-376 (2004)

10. D.U. Shah, Mater. Des. 62 21-31 (2014)

11. I. El Sawi, H. Bougherara, R. Zitoune, Z. Fawaz, J. Biobased Mater. Bioenergy 8(1) 69-76 (2014) 
12. H.L. Bos, K. Molenveld, W. Teunissen, A.M. van Wingerde, D.R.V. van Delft, J. Mater. Sci. 39 (6) 2159- 2168 (2004)

13. F. Bensadoun, K.A.M. Vallons, L.B. Lessard, I. Verpoest, A.W. Van Vuure, Compos Part A-Appl S 82 253-266 (2016)

14.Z. Mahboob, I. El Sawi, R. Zdero, Z. Fawaz, H. Bougherara, Compos Part A-Appl S 92 118-133 (2017)

15. M. Kersani, S.V. Lomov, A.W. Van Vuure, A. Bouabdallah, I. Verpoest, J. Compos Mater. 49 (4) 403-413 (2015)

16.G. Coroller, A. Lefeuvre, A. Le Duigou, A. Bourmaud, G. Ausias, T. Gaudry, C. Baley, Compos Part A-Appl S 51 62-70 (2013)

17. B. Lamy, C. Pomel, J. Mater. Sci. Lett. 21(15) 1211$1213(2002)$

18. J.M.F.A. Blanchard, A.J. Sobey, J.I.R. Blake, Compos Part B-Eng 84 228-235 (2016)

19. J.P. Torres, L.J. Vandi, M. Veidt, M.T. Heitzmann, Compos Part A-Appl S 98 99-104 (2017)

20. S. Liang, L. Guillaumat, P.-B. Gning, Int J Impact Eng 80 56-64 (2015)
21. R. Petrucci, C. Santulli, D. Puglia, E. Nisini, F. Sarasini, J. Tirillo, L. Torre, G. Minak, J.M. Kenny, Compos Part B-Eng 69 507-515 (2015)

22. M. Ravandi, W.S. Teo, L.Q.N. Tran, M.S. Yong, T.E. Tay, Compos Part B-Eng 117 89-100 (2017)

23. L. Yan, N. Chouw, K. Jayaraman, Compos Part BEng 63 15-26 (2014)

24. L. Yan, N. Chouw, K. Jayaraman, Mater. Des. 56 528-541 (2014)

25. H. Yu, Y. Guo, X. Lai, Mater. Des. 30(7) 2501-2505 (2009)

26. J. Xu, W. Zhang, X. Gao, W. Meng, J. Guan, PLoS One 11(3) (2016)

27. B. Gu, F.-K. Chang, Aerosp. Sci. Technol. 11(7-8) 535-545 (2007)

28. P. Frontini, S. Lotfian, M.A. Monclus, J.M. MolinaAldareguia, Exp. Mech. 55(5) 851-862 (2015)

29.N.K. Naik, K.S. Pandya, V.R. Kavala, W. Zhang, N.A. Koratkar, J. Compos Mater. 49(8) 903-910 (2015)

30.F. Xu, W.-g. Guo, K.-k. Fu, X.-j. Wang, Acta Polymerica Sinica (9) 1092-1099 (2015) 
